\title{
Listeriosis probe identifies multiple deficiencies
}

$\mathrm{L}$

ast year's deadly listeriosis outbreak was largely caused by inadequate reporting requirements, insufficient coordination of government departments and a failure to properly communicate to Canadians how to minimize the risk of becoming sick, says a report released yesterday by an independent investigator.

The report, ordered by Prime Minister Stephen Harper, concluded a 6month investigation into the outbreak by Sheila Weatherill, former president of the Edmonton Health Authority.

Weatherill paints a picture of a food safety system that contained gaps at nearly every level from prevention to reporting and to the emergency response protocol.

The gaps consisted of missing reporting requirements for meat processors, a food safety worker shortage and several government agencies that did not clearly understand how they were to work together to prevent or minimize an outbreak.

"The food safety system did not work as perfectly as it needed to," Weatherill said at a press conference. "Much more must be done to make sure it doesn't happen again."

The outbreak, which became public in August, 2008, occurred in a Maple Leaf Foods plant in Toronto, Ontario and eventually killed 22 Canadians and infected many others. Weatherill found that nearly $80 \%$ of those infected by the illness lived in long-term care homes or were in hospitals that served tainted meats.

Evidence of contamination was available months before the outbreak occurred, but there was insufficient monitoring and no legal obligation to report the contamination. Maple Leaf has since apologized, agreed to pay up to $\$ 27$ million to settle class-action lawsuits and introduced more rigorous testing at its plants.

Weatherill's report recommends that the Public Health Agency of Canada (PHAC), and not the federal Agricul-

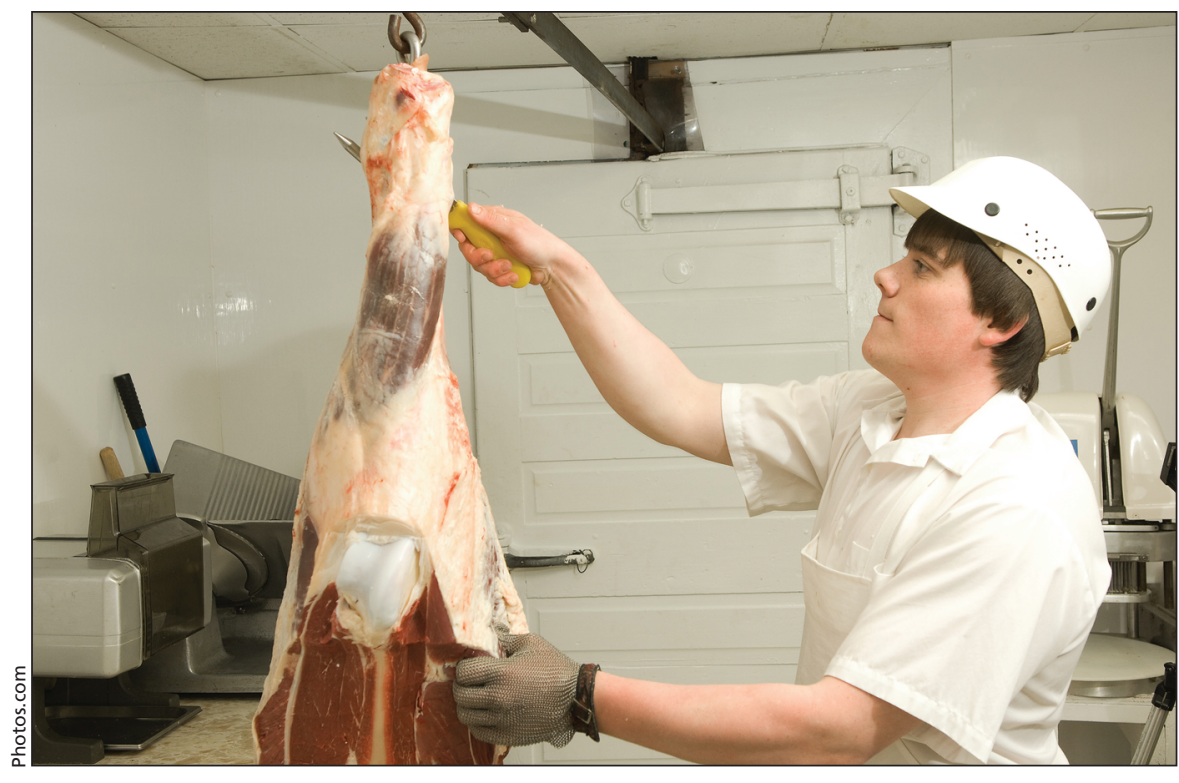

Prime Minister Stephen Harper's appointed listeriosis investigator says meat processing companies should be obliged to alert the federal government to health threats.

ture Minister, take charge of communications during an outbreak because citizens prefer to hear from health officials, and not politicians, during a health crisis.

Consolidating public health response under one agency has been a key recommendation of reports dating back to the 2003 SARS outbreak.

"This is not a new story," says Dr. Kumanan Wilson, Canadian Research Chair in Public Health Policy at the University of Ottawa. "These aren't new concepts or new themes, so why do they remain persistent problems?"

$\mathrm{He}$ adds that it was especially crucial to hear from public health officials because the listeria outbreak had economic implications on the meat industry, and occurred on the eve of a federal election. "That's even more reason that we need to know this is being managed from a public health perspective and not a political, economic or other perspective."

Coordinating communications under one agency is also necessary because, the report says, the government did a poor job of informing the public about the outbreak. Despite the fact that such a large proportion of those infected were elderly and in long-term care homes or hospitals, many Canadians did not know which segments of the population were at risk or which foods to avoid.

In all, Weatherill's report makes 57 recommendations to prevent a similar outbreak from occurring again. Broadly, they reflect Weatherill's findings that there was an insufficient focus on food safety among senior management in both the public and private sectors, not enough advance planning was done to leave both sectors ready in the event of an outbreak and that the responsible agencies lacked a sense of urgency at the outset of the outbreak.

"There are simply no easy answers," Weatherill said. "Last summer's outbreak was a rare and complex event that defies simple explanations."

Specifically, Weatherill recommends that meat processors be required to report health threats to the Canadian Food Inspection Agency, rather than the voluntary reporting mechanism in place at the time of the outbreak. 
The report states meat processors need to work more closely with equipment manufacturers so that cleaning protocols and product design reflect the need to improve sanitation.

The Canadian Food Inspection Agency should conduct a third party audit to determine the appropriate number of inspectors the agency needs, how many plants an inspector can safely be responsible for and also identify training needs, the report adds.

Weatherill's mandate did not allow her to express findings of criminal or civil liability.

The investigation is among a series that have been conducted into the outbreak, including ones by the food inspection agency, Health Canada and PHAC, which all found that poor coordination of food safety was a significant reason behind the outbreak.

Opposition members of parliament on a House of Commons subcommittee studying food safety have called for a public inquiry into the outbreak.
At a brief news conference, Agriculture Minister Gerry Ritz called the report a "road map" for improving Canada's food safety system and said the federal government will not compensate the families of listeriosis victims.

Weatherill's report asks the federal government to report back to Canadians within 2 years on the implementation of its recommendations. Christopher Mason, Ottawa, Ont.

DOI:10.1503/cmaj.109-3001 